\title{
O tema jogo infantil no periódico Pro-posições
}

\author{
Flávia Roberta dos Santos Pereira \\ Litza Pereira Santos \\ Karen Santos Amorim \\ Lílian Miranda Bastos Pacheco
}

\begin{abstract}
Resumo
Este trabalho pretende analisar os artigos sobre o tema jogo na Educação Infantil no periódico Pro-Posições de 1990 a 2003. A atividade lúdica é de extrema importância na infância, sendo uma das formas da criança entrar em contato com a realidade. Seis artigos foram analisados, segundo os critérios: data de publicação, autoria, filiação institucional, objeto de estudo, enfoques teórico/metodológico e conclusões dos estudos. As análises indicam que a frequência dos estudos aumentou consideravelmente desde 1994. Os autores são mulheres, professoras ou alunas, ligadas à pós-graduação nas Regiões Sul/Sudeste de universidades públicas. As pesquisas investigam relações entre jogo e desenvolvimento, brincar, cultura; fundamentam-se nas abordagens psicogenética, sócio-cultural ou na filosofia analítica; e envolvem estudos empíricos ou teóricos. Os artigos destacam a importância de se aprofundar os estudos sobre este momento da educação, em que funções maternas e educacionais se confundem, reunindo as potencialidades da atividade lúdica às necessidades da criança.
\end{abstract}

Palavras-chave: Educação Infantil, jogos, brincadeiras.

\section{The theme "kids game" in the periodic Pro-posições}

\begin{abstract}
This study analyzes articles on the topic Game in Childhood Education, in the journal Pro-Positions, from 1990 to 2003. Leisure activity is important in childhood. It is one of the ways children get in touch with reality. Six articles were analyzed, according to the following criteria: publication date, authors, institutional affiliation, and objective of the study, theoretic and methodological approaches, and conclusions of the studies. Analyses indicate that the frequency of the studies has increased considerably since 1994. The authors are women, teachers and students, linked to a post-graduation course in public universities in the South and Southeast Regions of Brazil. The work investigated relationships among game and development, play, and culture. The study was oriented by psychogenetic, socio-cultural approaches or by analytical philosophy involving theoretical or empirical studies. The articles highlight the importance of deepening the studies on this moment of education, in which maternal and educational functions are confusing, bringing together the potential of leisure activity to the needs of the child.
\end{abstract}

Keywords: Early childhood education, games, tricks.

\section{El tema juego infantil en el periódico Pro-posições}

\section{Resumen}

Este trabajo pretende analizar los artículos sobre el tema Juego en la Educación Infantil en el periódico Pro-Posições, en la década de 1990 a 2003. La actividad lúdica es de extremada importancia en la infancia, siendo una de las formas del niño entrar en contacto con la realidad. Seis artículos fueron analizados, según los criterios: fecha de publicación, autoría, afiliación institucional, objeto de estudio, enfoques teórico/ metodológicos, conclusiones de los estudios. Los análisis indican que la frecuencia de los estudios aumentó considerablemente dese 1994. Los autores son mujeres, profesoras o alumnas de postgrado de las regiones Sur/Sudeste, en universidades estatales. Las investigaciones examinan las relaciones entre el juego y: desarrollo, jugar, cultura; basándose en las visiones psicogenética, socio-cultural o en la filosofía analítica; involucran estudios empíricos o teóricos. Los artículos destacan la importancia de profundizar los estudios acerca de este momento de la educación, en el que funciones maternas y educativas se confunden, uniendo las potencialidades de la actividad lúdica a las necesidades de los niños.

Palabras-clave: Educación Infantil, juegos, jugueteos. 


\section{Introdução}

Este trabalho objetiva identificar e analisar descritivamente as produções acadêmicas no periódico ProPosições que abordam o tema jogo na Educação Infantil. Esta é a primeira etapa do Ensino Básico, que envolve crianças de zero a seis anos de idade. Neste período da vida, elas exploram intensamente seu imaginário, dedicando a maior parte de seu tempo ao jogo e às brincadeiras. A atividade lúdica é um tema de especial importância nesta fase do desenvolvimento humano por ser uma das formas mais naturais da criança entrar em contato com a realidade, além de apreender o mundo, os objetos e os fenômenos. Prova disto é que inúmeros pedagogos e psicólogos estão de acordo com a ideia de que o jogo infantil é uma atividade física e mental que favorece tanto o desenvolvimento pessoal como a sociabilidade. Ele contempla situações de conflitos, submissão a regras, harmonia, ordem, tensão, entre outras.

Situada a importância do jogo para o desenvolvimento da criança, levanta-se a seguinte questão: quais as características da produção acadêmica sobre o tema jogo, na Educação Infantil, divulgada no periódico Pro-Posições de 1990 a 2003? Esta fonte documental foi escolhida por ter sido avaliada pela QUALIS-CAPES - ano base 2003, na área de Educação, com conceito $A$, ser de circulação nacional e estar vinculada a programa de pós-graduação em Educação.

No periódico em questão, os estudos na área da Educação Infantil sobre jogo e brincar aparecem, entre outros temas, como: concepções, desenvolvimento da criança, formação de profissionais, política educacional, necessidades especiais, gênero, literatura infantil, produção acadêmica e propostas ou práticas educacionais. Notase uma abrangência temática. Dos 50 artigos no campo da Educação Infantil, o tema jogo representa $12 \%$ deste universo, ou seja, seis artigos foram publicados no período analisado.

Além da diversidade de enfoques e objetos de estudos, o periódico Pro-Posições veicula em seus fascículos diferentes tipos textuais, principalmente artigos e resenhas. O presente estudo analisa apenas o primeiro tipo.

Os artigos foram selecionados caso apresentassem explicitamente no título, palavras-chave ou resumo os seguintes descritores: creche, pré-escola, educação infantil, zero a seis anos, criança, infância e, concomitantemente com qualquer um destes, jogo, brincadeira ou brinquedo.

Para analisar os textos, os seguintes critérios foram considerados: data de publicação; autoria e filiação institucional; objeto de estudo; enfoques teórico e metodológico e conclusões dos estudos.

\section{Data da Publicação}

A análise dos documentos indicou que, apesar da pesquisa abranger os anos de 1990 a 2003, o tema jogo só aparece a partir de 1994. Desde então, a temática é recorrente, totalizando seis artigos no período.

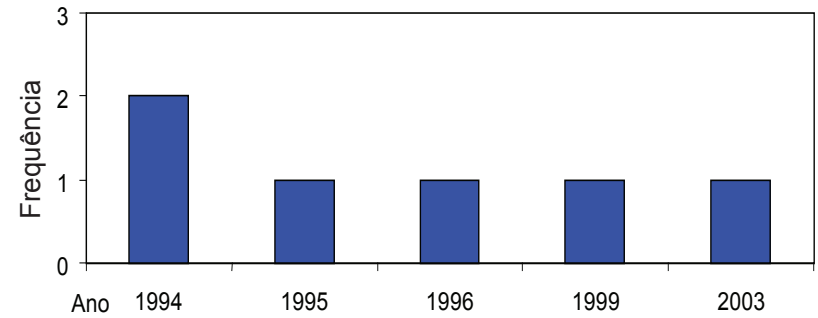

Figura 1. Número de publicações por ano.

Pode-se observar, na Figura 1, que o único ano no qual houve duas publicações foi o de 1994, os demais artigos foram publicados em anos esparsos.

\section{Autoria e Filiação Institucional}

Os artigos possuem autores diferentes, sendo que, em todos eles, o autor é do gênero feminino, o que reafirma a tradição da Educação Infantil como uma área de conhecimento de domínio predominantemente de mulheres.

Três delas são professoras e três são alunas de Pós-Graduação na área de Educação Infantil, ligadas a universidades públicas das Regiões Sudeste ou Sul. Uma professora e uma aluna possuíam, na época da publicação, vínculo com a Universidade de São Paulo - USP, as outras quatro estavam ligadas à Universidade Estadual de Campinas - UNICAMP.

Em se tratando da profissão das alunas, duas eram professoras da Universidade Federal de Santa Catarina UFSC e uma não declarou vínculo empregatício. Nota-se um engajamento das autoras com a vida acadêmica e com a área de conhecimento em questão - a Educação Infantil.

\section{Objeto de Estudo}

Conforme a Tabela 1, os artigos foram agrupados segundo seus objetos de estudo, inferidos a partir das palavras-chave indicadas pelas próprias autoras e ratificadas por informações obtidas na leitura do texto completo.

Os dois estudos sobre desenvolvimento da criança foram publicados no mesmo volume. O texto de Orly Assis (1994) aborda a evolução do jogo e o desenvolvimento da função simbólica na criança. Já o de Rosely Brenelli (1994) investiga a exposição da criança aos jogos com regras e suas relações com o desempenho escolar e desenvolvimento cognitivo.

A respeito de jogo e brincadeira, diferentes conceitos são apresentados por Tizuko Kishimoto (1995), enquanto que Gisele Wajskop (1996) analisa as concepções de mães e profissionais de pré-escola sobre o brincar e a educação. 
Tabela 1. Frequência da categoria objeto de estudo por ano.

\begin{tabular}{|c|c|c|c|c|c|c|}
\hline \multirow[b]{2}{*}{ Objeto de Estudo } & \multicolumn{5}{|c|}{ Ano de Publicação } & \multirow[b]{2}{*}{ Total } \\
\hline & চ্ & $\begin{array}{l}\text { Љ } \\
\stackrel{\circ}{\leftarrow}\end{array}$ & $\begin{array}{l}\mathscr{S} \\
\stackrel{\circ}{\circ}\end{array}$ & হু & ঙ̊ & \\
\hline Desenvolvimento da criança & 2 & & & & & 2 \\
\hline Jogo e Brincar & & 1 & 1 & & & 2 \\
\hline Cultura infantil & & & & 1 & 1 & 2 \\
\hline Total & 2 & 1 & 1 & 1 & 1 & 6 \\
\hline
\end{tabular}

Tabela 2. Abordagem teórica por ano de publicação

\begin{tabular}{|c|c|c|c|c|c|c|}
\hline \multirow[b]{2}{*}{ Abordagem Teórica } & \multicolumn{5}{|c|}{ Ano de Publicação } & \multirow[b]{2}{*}{ Tota } \\
\hline & 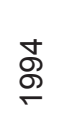 & 뇨 & $\begin{array}{l}\text { Љ } \\
\stackrel{-}{-}\end{array}$ & ஓ্ & ঙ̊̊ & \\
\hline Psicogenética & 2 & & & & & 2 \\
\hline Filosofia Analítica & & 1 & & & & 1 \\
\hline Sócio-cultural & & & 1 & 1 & 1 & 3 \\
\hline Total & 2 & 1 & 1 & 1 & 1 & 6 \\
\hline
\end{tabular}

Mais recentemente, a cultura infantil tem sido enfatizada como objeto de estudo. Sobre esse aspecto, Patrícia Prado (1999) investiga se as crianças pequenas produzem cultura e Daniela Finco (2003) observa as relações de gênero nas brincadeiras das crianças.

\section{Abordagem Teórica}

Assim como podem ser encontrados diferentes focos de interesses dentre os estudos sobre jogos na Educação Infantil ao longo do tempo, o mesmo ocorre com a fundamentação teórica utilizada.

Como se pode verificar na tabela 2 , os artigos se fundamentam na abordagem Psicogenética (Assis, 1994; Brenelli, 1994), na Filosofia Analítica (Kishimoto, 1995) ou na abordagem Sócio-Cultural (Finco, 2003; Prado, 1999; Wajskop, 1996). Nota-se uma tendência cada vez maior de estudos que consideram não apenas o sujeito em questão, mas também o contexto cultural da sociedade em que está inserido, destacando a influência deste na formação dos indivíduos.

\section{Abordagem Metodológica}

Nos seis artigos analisados, há dois estudos empíricos que analisam grupos específicos de crianças (Brenelli, 1994; Finco, 2003); assim como quatro revisões bibliográficas, apresentando reflexões teóricas (Assis,1994; Prado, 1999), conceitos (Kishimoto, 1995) ou concepções de adultos sobre o brincar e a educação (Wajskop, 1996).

Na Tabela 3, que mostra os sujeitos da pesquisa, pode ser observada a inclusão de um artigo sobre crianças de oito a onze anos de idade, ou seja, da antiga terceira série primária. Esta pesquisa foi mantida neste estudo porque, apesar de não se referir à Educação Infantil, apresenta os efeitos do uso pedagógico de jogos com regras no desenvolvimento da criança, a partir de dados empíricos.

Em dois dos artigos, aparece o termo Educação Pré-escolar (Assis, 1994; Wajskop, 1996) e um refere-se à creche (Prado, 1999). Portanto, observa-se ainda a presença de diversas nomenclaturas para este nível de escolaridade que antecede o Ensino Fundamental, atualmente nomeada de Educação Infantil. 
Tabela 3. Sujeitos de cada pesquisa por ano de publicação.

\begin{tabular}{c|c|c|c|c|c|c|c}
\hline \multicolumn{2}{c}{ Sujeitos da Pesquisa } & 1994 & 1995 & 1996 & 1999 & 2003 & Total \\
\cline { 3 - 8 } & & & & & & 1 & 1 \\
\hline \multirow{2}{*}{ Crianças } & 4 a 6 anos & 1 & & & & & 1 \\
\cline { 2 - 8 } & 8 a 11 anos & 1 & 1 & 1 & 1 & & 4 \\
\hline \multicolumn{2}{c}{ Bibliografias } & 2 & 1 & 1 & 1 & 1 & 6 \\
\hline
\end{tabular}

\section{Conclusões dos Estudos}

Cada estudo trata de importantes aspectos da educação da criança de zero a seis anos. Em seu artigo, Assis (1994) apresenta a classificação e a evolução do jogo, na concepção piagetiana, desde as atividades sensóriomotoras, nos primeiros dois anos de vida, passando pelas brincadeiras de faz-de-conta ou jogos simbólicos, até a imitação exata da realidade; e ainda a importância do jogo para a Educação Infantil. Destaca que o jogo simbólico tem início com os esquemas e como ponto de chegada às construções simbólicas. Os jogos são classificados segundo a própria estrutura e compreendidos como instrumentos de assimilação lúdica. O jogo simbólico tem uma importância funcional para o desenvolvimento do pensamento e das relações sócio-afetivas das crianças na educação préescolar.

Brenelli (1994) procura discutir o efeito dos jogos com regras no desenvolvimento cognitivo de crianças que estão na terceira série do ensino fundamental de uma escola pública e que apresentam dificuldades de aprendizagem. Para realizar essa análise, utiliza um grupo experimental e um grupo controle buscando verificar se atividades de jogos com regras, como Quilles e Cilada, têm implicações no desenvolvimento operatório e na compreensão da aritmética. Concluiu que o modo como as crianças jogavam e compreendiam as relações utilizadas no jogo tinha influência do seu nível de desenvolvimento operatório. Observou, também, que as crianças do grupo experimental, em comparação com as do grupo controle, apresentaram nítido progresso em noções operatórias e aritméticas. Esse resultado mostra a validade de utilizar atividades lúdicas em intervenções pedagógicas.

Kishimoto (1995) discute o conceito de jogo na Educação Infantil, afirmando que este depende da concepção que se tem de criança. Busca, ainda, definir jogo diferenciando-o de brinquedo e brincadeira, para tanto cita algumas características do jogo propostas por Huizinga (1951) e contrapõe estas citando outros autores. Encerra seu texto apresentando diferentes tipos de jogos e suas analogias.
Wajskop (1996) analisa as concepções das mães e profissionais sobre a relação existente entre o brincar e a educação, bem como as práticas pedagógicas presentes na pré-escola. Seu objetivo é compreender a diversidade das propostas escolares encontradas em São Paulo e sua relação com o status da infância em nossa sociedade. A autora averiguou que, nas pré-escolas públicas tanto de São Paulo quanto de Paris, ainda se privilegiava o ensino de conteúdos e treino de hábitos e atitudes, concebendo o espaço da brincadeira apenas como recreação. Ela não constatou a ideia das professoras sobre a brincadeira considerada como atividade importante para o desenvolvimento sócio-cultural da criança. A autora alerta para a necessidade de se refletir sobre as práticas institucionais, defendendo a concepção da criança como parceira nas interações sociais e seu direito de brincar.

Prado (1999) observa a produção cultural das crianças de zero a três anos no intuito de compreender se os pequenos produzem cultura. Busca, também, identificar as concepções do brincar na Educação Infantil, assim como dar uma contribuição para a construção da Pedagogia da Educação Infantil. Em sua análise, ela concluiu que a creche deve proporcionar espaços para brincar, em que adultos e crianças possam vivenciar, experimentar, sentir, conhecer, explorar toda a riqueza que esta atividade encerra, entre fantasias e histórias, danças, músicas, transgressões, imprevistos, sociabilidades, invenções e expressões culturais de crianças pequenininhas. Os dados de observação não estão presentes no artigo, eles fazem parte do trabalho de mestrado da autora. Em sua análise, ela chega à conclusão de que o sujeito pequeno está inserido histórico-socialmente e que, mesmo sem dominar a fala, é um sujeito da linguagem e, portanto, fazedor de cultura.

Finco (2003) destaca a relação de gênero nas brincadeiras infantis, numa tentativa de refletir sobre a troca dos papéis sexuais nas brincadeiras de alunos em uma escola municipal de Educação Infantil. O que pretende é trabalhar a concepção de criança não do ponto de vista "adultocêntrico", mas partindo do pressuposto de que ela é um indivíduo capaz, produtor e portador de cultura. A autora confirma sua hipótese "de que as crianças não possuem 
práticas sexistas em suas brincadeiras e, portanto, não reproduzem os papéis sexuais cristalizados presentes no mundo adulto".

\section{Considerações Finais}

No periódico Pro-Posições, no período de 1990 a 2003, foram encontrados seis artigos, a partir de 1994, todos escritos por professoras ou alunas de Pós-Graduação de universidades públicas das Regiões Sudeste ou Sul.

Os estudos tratam do jogo relacionado com o desenvolvimento da criança, a cultura infantil e o brincar, tendo por base a abordagem psicogenética, a sócio-cultural ou a filosofia analítica, que tem como sujeitos crianças ou bibliografias.

Todos os artigos destacam a importância de se aprofundar os estudos sobre este momento da educação tão peculiar, em que as funções maternas e educacionais se confundem tanto, reunindo as potencialidades da atividade lúdica às necessidades de educação da criança pequena. Diferentes formas de jogo vão ter uma importância especial ao longo do desenvolvimento da criança. Durante os primeiros anos de vida, principalmente dos dois aos seis anos, a criança vivencia importantes descobertas no reino da linguagem. Passa a se comunicar e a pensar através das imagens e palavras.

Nesse processo de formação, o jogo simbólico desempenha um papel crucial. Gradativamente a criança vai organizando suas estruturas mentais passando a compreender as regras do jogo. Antes disso, começa a participar das brincadeiras como "café com leite", quando os colegas maiores, para inserir a criança pequena, concedemIhe determinadas licenças durante o brincar.

É importante que os profissionais da Educação Infantil conheçam os efeitos não só do jogo simbólico, mas também do jogo com regras, pois não há um tempo estabelecido para a criança começar a perceber as exigências das necessidades lógicas e inferir as noções de conservação, assim como reconhecer os direitos e os deveres de cada um no jogo.
A experiência do brincar estimula o sujeito à interação e ao diálogo, apresenta-lhe valores, modos e costumes da sua cultura. Ao olhar para os jogos e brincadeiras infantis, o pesquisador, o professor e o adulto têm acesso à compreensão das especificidades da criança pequena, reconhecendo-a como produtora de cultura. Através dos jogos e das brincadeiras infantis, podem ser observadas as genuínas posturas e elaborações destes pequenos sujeitos sobre os papéis sexuais.

Como se pode ver, os estudos no campo da Educação Infantil explicitam os diferentes enfoques nesse campo de conhecimento específico, através de um olhar multidimensional e integrador. Há, ainda, muito que se investigar e principalmente socializar, levando estas discussões até os cursos de formação de professor ou sessões de orientação pedagógica das escolas.

\section{Referências}

ASSIS, O. Z. M. (1994). O jogo simbólico na teoria de Piaget. ProPosições, 5(1), 99 -108.

BRENELLI, R. P. (1994). A influência de atividades com os jogos Quilles e Cilada no desempenho operatório e na compreensão de noções aritméticos em Crianças com dificuldades de aprendizagem. Pro-Posições, 5(1), 21-36.

FINCO, D. (2003). Relações de gênero nas brincadeiras de meninos e meninas na educação infantil. Pro-Posições, 14(3), 89 -101.

HUIZINGA, J. (1951). Homo Ludens: O jogo como elemento da cultura. São Paulo: Perspectiva.

KISHIMOTO, T. M. (1995). O jogo e a educação infantil. ProPosições, 6(2), 46-63.

PRADO, P. D. (1999). As crianças pequenininhas produzem cultura? Considerações sobre educação e cultura infantil em creche. ProPosições, 10(1), 110-118.

WAJSKOP, G. (1996). A brincadeira infantil na educação pré-escolar paulista e parisiense: o que pensam sobre elas os adultos?. ProPosições, 7(3), p.51 -64.
Recebido em: 17/04/2008

Reformulado em: 03/07/2009

Aprovado em: 16/07/2009

\section{Sobre as Autoras}

Flávia Roberta dos Santos Pereira

Graduanda em Licenciatura em Pedagogia pela Universidade Estadual de Feira de Santana - DEDU/UEFS - BA. Bolsista IC/ PROBIC/UEFS.

\section{Litza Pereira Santos}

Graduanda em Licenciatura em Pedagogia pela Universidade Estadual de Feira de Santana - DEDU/UEFS - BA. Bolsista IC/ FAPESB

Karen Santos Amorim, Graduanda em Licenciatura em Pedagogia pela Universidade Estadual de Feira de Santana - DEDU/UEFS - BA. Membro do Grupo de Pesquisa Desenvolvimento Humano e Processos Educativos - DEHPE.

\section{Lílian Miranda Bastos Pacheco}

Doutora pela Faculdade de Educação da Universidade Estadual de Campinas - FE/UNICAMP. Professora Adjunta do Departamento de Educação da Universidade Estadual de Feira de Santana - DEDU/UEFS - BA. 